\title{
Sudden Severe Bradycardia in a Child Following Induction Dose of Cisatracurium: A Rare Entity
}

\author{
Sourav Burman ${ }^{1}$ \\ ${ }^{1}$ Department of Neuroanaesthesiology and Critical Care, All India \\ Institute of Medical Sciences (AlIMS), New Delhi, India
}

J Neuroanaesthesiol Crit Care 2021;8:149-150.

The cardiac output in children is largely dependent on heart rate (HR), and bradycardia in pediatric patients can be alarming. Bradycardia has been reported to occur at various stages of anesthesia and surgery. Factors precipitating bradycardia are drugs (28\%), airway-related events (16\%), autonomic reflexes (14\%), and regional anesthesia (9\%). ${ }^{1}$ Various drugs in an anesthetist's armamentarium are known to cause bradycardia. However, cisatracurium is considered a safe drug that does not cause histamine release or produce clinically important cardiovascular effects. ${ }^{2}$ Here, we describe a rare incidence of sudden severe bradycardia within minutes of administration of an intubating dose of cisatracurium.

A 6-year-old, 18-kg boy, American Society of Anesthesiologists (ASA) physical status class I, was scheduled for craniotomy and excision of a sellar-suprasellar mass $(4.5 \times 3.5 \times$ $3.2 \mathrm{~cm}$ ) under general anesthesia (GA). In the operating room, standard ASA monitoring was started. The preinduction vitals including HR, noninvasive blood pressure, and oxygen saturation were 127 beats/minute, $90 / 50 \mathrm{~mm} \mathrm{Hg}$, and $100 \%$, respectively. The child was preoxygenated and anesthesia was induced with gradual increasing concentrations of sevoflurane in oxygen, with the child breathing spontaneously. Once the child was unconscious, sevoflurane concentration was decreased to $3 \%$, an intravenous (i.v.) access was secured, and fentanyl $30 \mu \mathrm{g}$ i.v. was administered. After achieving deep plane of anesthesia (minimum alveolar concentration [MAC]: 1.5), adequate bag mask ventilation was confirmed, and cisatracurium $2.5 \mathrm{mg}$ (Cisatracurium Besylate Injection USP; Themis Medicare Ltd., Haridwar, Uttarakhand, India) was administered to facilitate tracheal intubation. Within 2 minutes after administering cisatracurium there was a sudden episode of bradycardia and the HR decreased from 122 to 58 beats/minute. The ECG waveform over the monitor showed a sinus bradycardia; however, there was no associated hypotension or desaturation. Imme-
Address for correspondence Mihir P. Pandia, MD, Department of Neuroanaesthesiology and Critical Care, Room No. 709, Neurosciences Centre, All India Institute of Medical Sciences (AlIMS), New Delhi 110029, India (e-mail: pandiamihir@gmail.com).

diately, sevoflurane was discontinued and 100\% oxygen was administered which, however, did not improve the HR. Atropine $(0.2 \mathrm{mg})$ was administered following which HR gradually increased to 130 beats/minute over the next 1 minute. Trachea was intubated and mechanical ventilation was started. Rest of the surgery was uneventful. At the end of surgery, trachea was extubated, and the patient was shifted to the intensive care unit for observation.

Bradycardia under GA can be deleterious in children and can precipitate cardiac arrest. Fastle and Roback reported the incidence of airway manipulation-related bradycardia to be 0.5 to $4 \%{ }^{3}$ The laryngeal mucosa and laryngeal muscles are richly innervated by the vagus nerve, and any manipulation including laryngoscopy is prone to cause bradycardia. Keenan et al, in their study, observed hypoxemia and bradycardia during the preinduction and postinduction phases in $20 \%$ infants. ${ }^{4}$ Bradycardia during anesthesia can also occur due to inadequate ventilation and consequent rise in $\mathrm{CO}_{2}$, leading to increase in intracranial pressure in patients with large intracranial mass lesions.

Sevoflurane is commonly used in pediatric practice because of its sweet odor and safe cardiovascular profile. It is nonarrhythmogenic and does not affect cardiac conduction system significantly up to 2.0 MAC. There are reports of bradycardia and associated drop in blood pressure (BP) ( $>20 \%$ from baseline) in children anesthetized with sevoflurane, but the BP and HR spontaneously reverted after discontinuation of sevoflurane. ${ }^{5}$ Fentanyl and other opioids have vagomimetic properties and high doses can cause bradycardia-requiring administration of atropine. ${ }^{6}$ Muscle relaxants such as succinylcholine have been found to cause bradycardia but newer muscle relaxants such as atracurium or cisatracurium are considered safe in pediatric patients. Other drugs that may cause bradycardia are $\beta$ blockers and calcium channel blockers.
Published online

November 20, 2019
DOI https://doi.org/

$10.1055 / \mathrm{s}-0039-1700487$

ISSN 2348-0548. (c) 2019. Indian Society of Neuroanaesthesiology and Critical Care.

This is an open access article published by Thieme under the terms of the Creative Commons Attribution-NonDerivative-NonCommercial-License, permitting copying and reproduction so long as the original work is given appropriate credit. Contents may not be used for commercial purposes, or adapted, remixed, transformed or built upon. (https://creativecommons.org/licenses/by-nc-nd/4.0/).

Thieme Medical and Scientific Publishers Pvt. Ltd. A-12, 2nd Floor, Sector 2, Noida-201301 UP, India 
In our case, during the event, the MAC of sevoflurane was 1.5 whereas fentanyl $<2 \mu \mathrm{g} / \mathrm{kg}$ was administered 5 minutes earlier and the child was being ventilated adequately. However, within 2 minutes of administering the intubating dose of cisatracurium and prior to laryngoscopy and any neck or airway manipulation the child developed sudden severe bradycardia. The fall in HR was not gradual over a period of time, but sudden, severe, and sustained after administration of cisatracurium, which reverted only after atropine was administered. After excluding all other causes, anaphylactic or anaphylactoid reaction following cisatracurium appears to be the possible cause for sudden severe bradycardia in our case. Although we did not assess serum tryptase/plasma histamine levels or perform immunoglobulin-E (IgE) assay in this case to confirm the diagnosis of anaphylactic reaction, we suggest laboratory testing to confirm the diagnosis even if there is an isolated symptom, such as bradycardia, and making a note of this in the medical record of the patient for future.

In literature, there are few reports of anaphylactic reaction (bradycardia, hypotension, cutaneous flushing, and bronchospasm) after administration of cisatracurium. ${ }^{7}$ However, isolated bradycardia has not been described. Although cisatracurium has a safe cardiovascular profile, this case highlights a rare and serious complication and delivers a word of caution regarding its use, especially in pediatric patients.

\section{Funding}

None.

\section{Conflict of Interest}

None declared.

\section{References}

1 Judith AL, Hermanides J, Houweling LP, Quak JL, David RC. Bradycardia in children during general anaesthesia. In: Fransisco R, Marquez B. Cardiac Arrhythmias-New Considerations. 1st ed Rijeka Croatia: Intech; 2012:343-356

2 Lien CA, Belmont MR, Abalos A, et al. The cardiovascular effects and histamine-releasing properties of 51W89 in patients receiving nitrous oxide/opioid/barbiturate anesthesia. Anesthesiology 1995;82(5):1131-1138

3 Fastle RK, Roback MG. Pediatric rapid sequence intubation: incidence of reflex bradycardia and effects of pretreatment with atropine. Pediatr Emerg Care 2004;20(10):651-655

4 Keenan RL, Shapiro JH, Kane FR, Simpson PM. Bradycardia during anesthesia in infants. An epidemiologic study. Anesthesiology 1994;80(5):976-982

5 Kraemer FW, Stricker PA, Gurnaney HG, et al. Bradycardia during induction of anesthesia with sevoflurane in children with Down syndrome. Anesth Analg 2010;111(5):1259-1263

6 Pagel PS, Farber NE, Cerebral physiology and effect of anesthetic drugs. In: Miller RD, ed. Miller's Anesthesia. 8th ed. Virginia, VA: Elsevier Saunders; 2015:710-715

7 Clendenen SR, Harper JV, Wharen RE: Jr, Guarderas JC. Anaphylactic reaction after cisatracurium. Anesthesiology 1997;87(3):690-692

\title{
Clipping of Cerebral Aneurysm in a Patient with Coarctation of Aorta: Anesthetic Management
}

\author{
Summit Bloria ${ }^{1}$ Neha Maheshwari ${ }^{1}$ Hemant Bhagat ${ }^{2}$
}

\footnotetext{
${ }^{1}$ Department of Anaesthesia, Postgraduate Institute of Medical Education and Research (PGIMER), Chandigarh, India

${ }^{2}$ Division of Neuroanaesthesia, Department of Anaesthesia and Intensive Care, Postgraduate Institute of Medical Education and Research (PGIMER), Chandigarh, India
}

J Neuroanaesthesiol Crit Care 2021;8:150-151.

We report perioperative management of a 45-year-old male patient with coarctation of aorta ( $\mathrm{CoA})$ posted for clipping of ruptured posterior inferior cerebellar artery (PICA) aneurysm. A 45-year-old male patient, a known hypertensive for

Published online

March 14, 2020
Dol https://doi.org/ 10.1055/s-0040-1701801 ISSN 2348-0548.
Address for correspondence Neha Maheshwari, MD, Department of Anaesthesia, Postgraduate Institute of Medical Education and Research (PGIMER), Sector-12, Chandigarh 160012, India (e-mail: nehadoc2705@gmail.com).

past 1 year, presented to this hospital with sudden onset of severe headache and drowsiness for 2 days. An urgent noncontrast computerized tomography (NCCT) head was done, which revealed intraventricular hemorrhage in third and

(C) 2020. Indian Society of Neuroanaesthesiology and Critical Care.

This is an open access article published by Thieme under the terms of the Creative Commons Attribution-NonDerivative-NonCommercial-License, permitting copying and reproduction so long as the original work is given appropriate credit. Contents may not be used for commercial purposes, or adapted, remixed, transformed or built upon. (https://creativecommons.org/licenses/by-nc-nd/4.0/).

Thieme Medical and Scientific Publishers Pvt. Ltd. A-12, 2nd Floor, Sector 2, Noida-201301 UP, India 